\title{
MicroRNA-451 regulates stemness of side population cells via PI3K/Akt/mTOR signaling pathway in multiple myeloma
}

\author{
Juan Du ${ }^{1, *}$, Shuyan Liu ${ }^{1, *}$, Jie He ${ }^{1}$, Xi Liu ${ }^{1}$, Ying Qu ${ }^{1}$, Wenqing Yan ${ }^{1}$, Jianling Fan ${ }^{1}$, \\ Rong Li ${ }^{1}$, Hao Xi ${ }^{1}$, Weijun Fu ${ }^{1}$, Chunyang Zhang ${ }^{1}$, Jing Yang ${ }^{2}$ and Jian Hou ${ }^{1}$ \\ ${ }^{1}$ Department of Hematology, The Myeloma and Lymphoma Center, Changzheng Hospital, The Second Military Medical \\ University, Shanghai, China \\ 2 Department of Lymphoma/Myeloma, Division of Cancer Medicine and Center for Cancer Immunology Research, The \\ University of Texas, MD Anderson Cancer Center, Houston, Texas, USA \\ * These authors have contributed equally to this work
}

Correspondence to: Jian Hou, email: houjian@medmail.com.cn

Keywords: multiple myeloma; side population; miRNA-451; PI3K/AKt/mTOR; stemness

Received: January 09, $2015 \quad$ Accepted: March 18, $2015 \quad$ Published: April 12, 2015

This is an open-access article distributed under the terms of the Creative Commons Attribution License, which permits unrestricted use, distribution, and reproduction in any medium, provided the original author and source are credited.

\section{ABSTRACT}

Side population (SP) cells are an enriched source of cancer-initiating cells with stemness characteristics, generated by increased ABC transporter activity, which has served as a unique hallmark for multiple myeloma (MM) stem cell studies. Here we isolated and identified MM SP cells via Hoechst 33342 staining. Furthermore, we demonstrate that SP cells possess abnormal cell cycle, clonogenicity, and high drug efflux characteristics, all of which are features commonly seen in stem cells. Interestingly, we found that bortezomib, $\mathrm{As}_{2} \mathrm{O}_{3}$, and melphalan all affected apoptosis and clonogenicity in SP cells. We followed by characterizing the miRNA signature of MM SP cells and validated the specific miR-451 target tuberous sclerosis 1 (TSC1) gene to reveal that it activates the PI3K/Akt/mTOR signaling in MM SP cells. Inhibition of miR-451 enhanced anti-myeloma novel agents' effectiveness, through increasing cells apoptosis, decreasing clonogenicity, and reducing MDR1 mRNA expression. Moreover, the novel specific PI3K/Akt/mTOR signaling inhibitor S14161 displayed its prowess as a potential therapeutic agent by targeting MM SP cells. Our findings offer insights into the mechanisms regulating MM SP cells and provide a novel strategy to overcome resistance to existing therapies against myeloma.

\section{INTRODUCTION}

Multiple myeloma (MM) is a clonal B-cell malignancy with terminally differentiated plasma cells. Despite remarkable progress made in the biology and treatment of the disease, it is still incurable $[1,2]$. It has long been postulated that a small population of cancer stem cells (CSCs) persist in bone marrow niches resulting in the development of refractory clones and disease relapse [3].

Previous groups have successively described various CSC phenotypes in MM, including CD138-/CD34- with memory B-cells (CD19+/CD27+) [4, 5], CD138-/CD19+ cells with cytoplasmic light chain-restricted (LCR) cells [6], CD19-/CD45low-/CD38high/CD138+ [7], and CD138+ cell [8]. However, the distinct myeloma CSC marker is still one of the most controversial issues. Side population (SP) cells, first described by Goodell et al.[9], are a subset of enriched progenitor cells exhibiting stemlike phenotypes with a distinct low Hoechst 33342, which has been widely used as a unique source for studying CSC when specific markers are unavailable. Even though a few studies have previously explored the stem-like properties and tumorigenicity of SP cells in comparison to the main population (MP) cells, an understanding of MM SP cells remain elusive [5, 10-13].

MicroRNAs (miRNAs) are a class of regulatory non-coding RNAs approximately 22 nucleotides in length and function primarily by targeting specific mRNA sequences [14]. MiRNAs have emerged as important regulators of CSCs, which lead to the initiation, development, and progression of many cancers $[15,16]$. 
The signaling pathway components regulating normal stem cell self-renewal are commonly aberrantly activated in many human cancers, serving as potential therapeutic targets. The signaling pathways are ideal candidates for miRNA-mediated regulation due to the sharp dosesensitive nature of regulatory effects [17]. In the case of MM SP cells, however, miRNAs serving as nodes of the cell signaling pathways are yet defined. Therefore, the goal of this study was to identify and investigate stemlike cell properties of MM SP cells through modulating miRNAs involved in the relevant signaling pathways so to advance development of novel and effective MM therapies targeting SP cells.

\section{RESULTS}

\section{SP cells existed in MM cell lines and primary MM cells}

To isolate and provide evidence that the SP cells exist in myeloma cells, we analyzed a panel of cell lines, including NCI-H929, RPMI 8226, KMS-11, LP-1, U266, and SKO, as well as seven primary myeloma cells with Hoechst 33342 staining. Cells were also incubated in the presence of verapamil $(100 \mu \mathrm{M})$, a chemical inhibitor of the ABC protein family of transporters, which inhibits the efflux of Hoechst as the negative control for SP cell. The MM cell lines were found to contain of SP cells, presented as a distinct "tail" in the flow cytometry analysis (Supplemental Fig. 1A and 1B), from 0.5\% 10.3\% and patients' samples ranged a minor population of SP from 0.04\% 2.0\% (Supplemental Fig. 1C and 1D). We then utilized NCI-H929 and KMS-11 cell lines, both of which showed a reliable and stable detected SP cell population, to further investigate the functional characteristics of SP cells.

\section{SP cells endowed with distinct stem cell characteristics in MM}

SP cells have inherent properties that distinguish them from MP cells from their less-differentiated progeny. To determine if MM stem-like cells exist in a relatively quiescent state, SP and MP cells isolated from the NCI-H929 and KMS-11 cell lines were examined for their cell cycle status. We found that NCI-H929 SP cells contained a significantly higher percentage cells in $\mathrm{G} 1 / \mathrm{G} 0$ phase $(58.19 \%)$ compared to MP cells, which only contained $8.77 \%$ of cells in G1/G0 phase (Fig. 1A). Approximately $35.71 \%$ and $6.1 \%$ of SP cells were in S and G2 phases, respectively, compared to $57.74 \%$ and $33.49 \%$ in MP cells. Similarly, a high percentage cells in G1/G0 phase were detected in SP cells in comparison to MP cells of KMS-11 cell line (Fig. 1A).
We next examined the self-renewal capacity of SP cells. We found SP cells to have high clonegenicity, requiring only 200 cells/plate to successfully grow into colonies (Fig. 1B). After 14 days in culture, SP cells generated larger and around 3 times as many the number of colonies derived from MP cells either in NCI-H929 or KMS-11 cell lines, demonstrating that SP cells have a stronger self-renewal and proliferative abilities.

In MM, the immunophenotyping of CSC is still a controversial topic $[4,5,12,13]$. We stained the cells with CD38, CD138, CD20, and CD19 antibodies to characterize the immunophenotypes of NCI-H929 and KMS-11. Consistent with previous studies [13], we observed both CD138- and CD138+ expression on SP and MP cells, with no significant difference in expression level between the two populations. We found no significant difference in CD20 and CD19 expression between SP and MP cells (Fig. 1C).

ABCB1 (MDR1), ABCC1 (MRP1), ABCC2 (MRP2), ABCC4 (MRP4), and ABCG2 (BRCP) are the main transporters in multidrug resistance (MDR) family known to possess the ability to exclude drugs as well as being present in CSCs. We detected expression of these transporters in SP and MP sorted from NCI-H929 and KMS-11 cells. ABCG2 transcripts were significantly enhanced in SP cells in comparison to MP cells in both myeloma cell lines. However, the expressions of ABCB1 was slight enhanced in SP cells compared to MP sorted from NCI-H929 cells, while ABCC1, ABCC2, and ABCC4 were somewhat reduced in both cell lines (Fig. 1D). And then, the ABCG2 protein expression level were confirmed by western blot assay (Fig. 1D). This observation is consistent with the concept of ABCG2 transporter being the most specific SP marker from the MDR family [18].

Recently, detection of ALDH activity has been touted as a marker of hematopoietic stem/progenitor cells [19]. To determine whether SP cells contain the high ALDH expression as well, we used the fluorescent Aldefluor assay to exam ALDH activity. We observed a significantly increase in Aldefluor activity in NCI-H929 SP cells $(57.8 \%)$ and KMS-11 SP cells $(24.7 \%)$ than compared to corresponding MP cells (Fig. 1E).

To evaluate tumorigenicity of SP cells in mice, a total of $1 \times 10^{5}$ of SP or MP cells was injected subcutaneously into NOD/SCID mice with 6 mice per group per time points. We observed two out of six mice injected with SP cells developed subcutaneous tumors with great tumor mass, whereas mice injected with MP cells did not develop any tumor (Fig. 1F). These results, combined with our previous studies, showed only a $40 \%$ tumor formation rate in NCI-H929 cells. We thus speculated that the tumorigenicity of NCI-H929 derives from SP cells since only SP fractions eventually developed tumors with the latency and tumor mass being consistent with previously reported data $[8,13]$. 

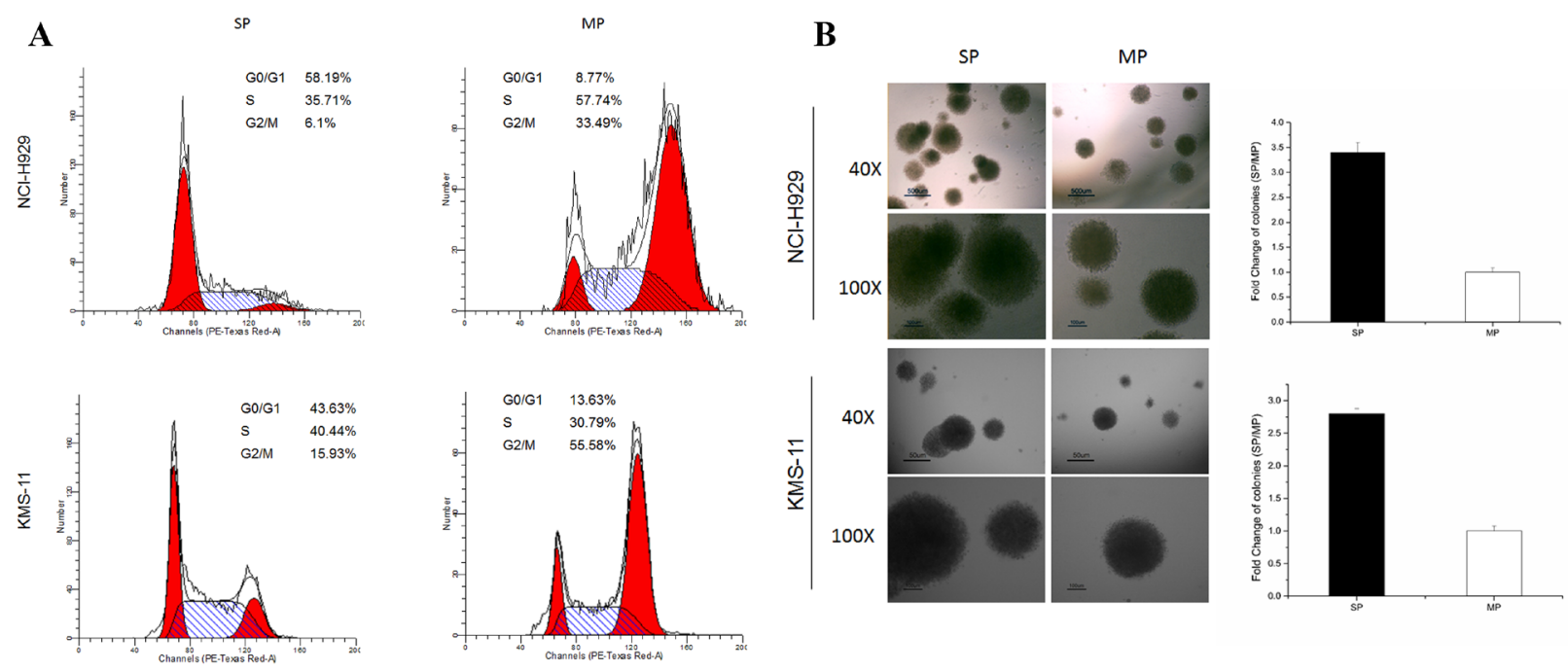

C
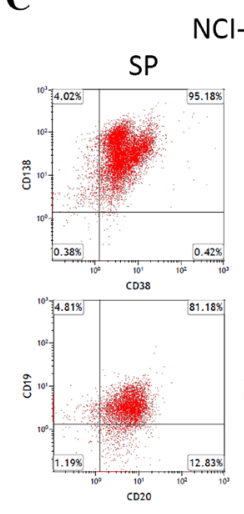

$\mathrm{Cl}-\mathrm{H} 929$
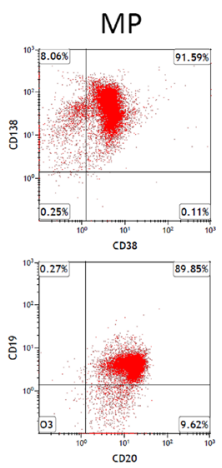

KMS-11
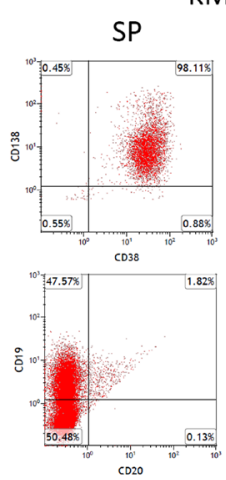

KMS-11 SP cells
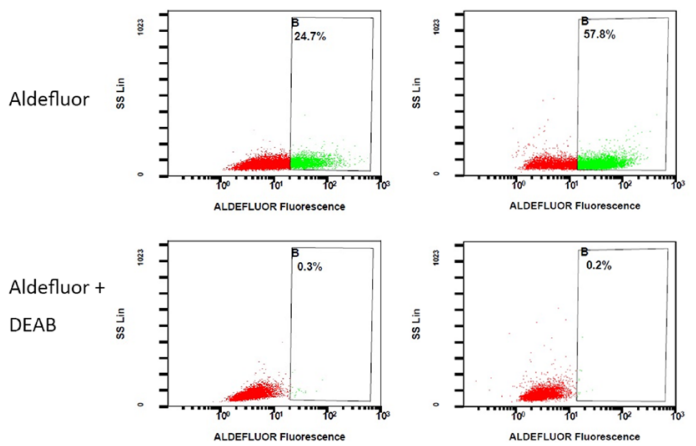

$\mathrm{NCl}-\mathrm{H} 929 \mathrm{SP}$ cells
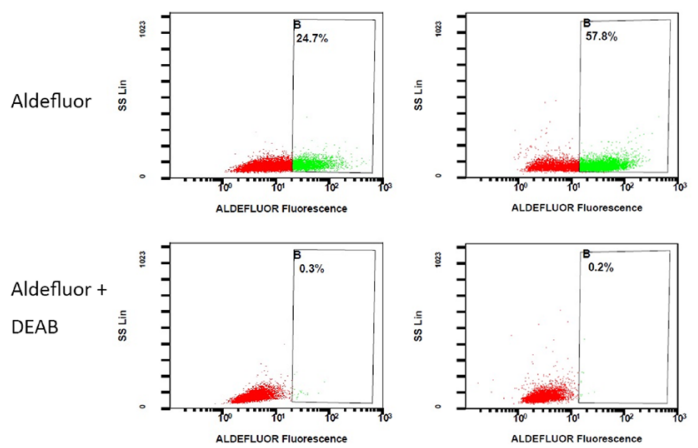
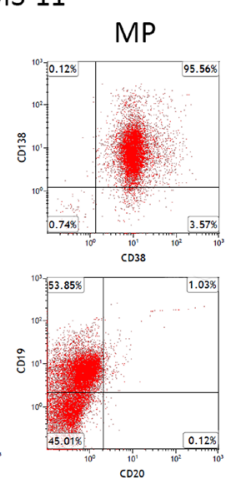
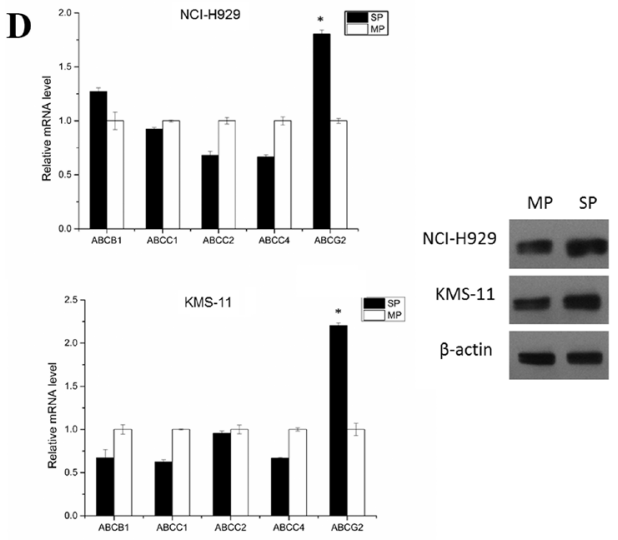

KMS-11

$\beta$-actin

\section{F}
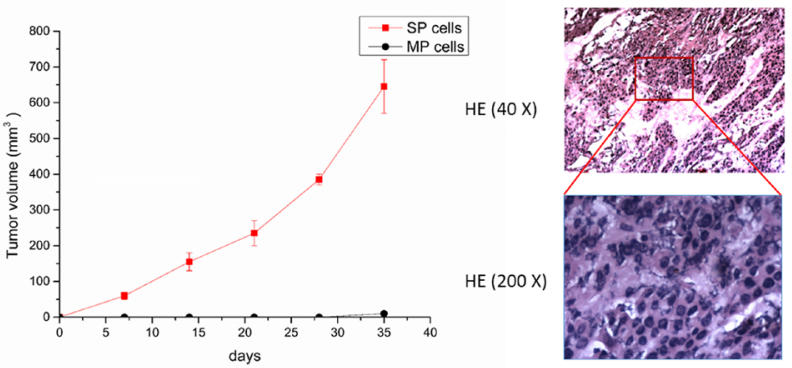

Figure 1: SP cells possess stem cell properties. A. Cell cycle analysis of SP or MP cells isolated from the NCI-H929 and KMS-11 cell lines after PI staining. B. CFC assay in sorted SP and MP cells isolated from the NCI-H929 and KMS-11cell lines was assessed after 14 days of culture (200 cells/plate). Representative images of colonies of sorted SP and MP are shown using an inverted microscope with a Nikon DXM1200F camera (magnification $40 \times \& 100 \times$ ). C. Cell surface phenotype of SP cells by fluorescence immunophenotyping assay for CD38, CD138, CD19, and CD20 expression in NCI-H929 and KMS-11 cells. D. qRT-PCR showing relative ABC transporter mRNA levels in SP and MP cells sorted from NCI-H929 and KMS-11 cells, respectively. ABCG2 expression increases significantly under stem cell conditions by qRT-PCR and western blot assays $\left({ }^{*} p<0.05\right)$. E. ALDH activity of SP and MP cells sorted from NCI-H929 and KMS-11 cells. A specific ALDH inhibitor (DEAB) as a negative control. Graph shows percentages of cells with increased ALDH activity within SP populations. All experiments were performed in triplicates. F. Tumorigenic formation potential of SP and MP cells. NOD/SCID mice were subcutaneously inoculated with SP or MP cells from $1 \mathrm{X} 10^{5}$ cells/mice. Caliper measurements of tumor diameters were measured every 7 days. H\&E stained images of tumor from SP mice groups with magnification of the selected areas. Scale bar, 40×, $200 \mu \mathrm{m} .200 \times, 50 \mu \mathrm{m}$. 
Table 1: Differential expression of miRNA identified in SP and MP cells.

\begin{tabular}{|c|c|c|c|}
\hline miRNA & $\begin{array}{c}\text { Chromosome } \\
\text { location }\end{array}$ & Fold change & $p$-value \\
\hline \multicolumn{4}{|l|}{ Upregulated miRNA } \\
\hline hsa-miR-33b & 17 & 6.987367677 & 0.0341726533 \\
\hline hsa-miR-326 & 11 & 6.612866664 & 0.0000050910 \\
\hline hsa-miR-335* & 7 & 4.805920365 & 0.0207873985 \\
\hline hsa-miR-144 & 17 & 4.107045945 & 0.0016160025 \\
\hline hsa-miR-451 & 17 & 3.801646299 & 0.0030331962 \\
\hline hsa-miR-363 & $\mathrm{X}$ & 3.685533855 & 0.0147515387 \\
\hline hsa-miR-4290 & 9 & 3.408334553 & 0.0006398131 \\
\hline hsa-miR-486-5p & 8 & 2.741136533 & 0.0012473680 \\
\hline hsa-miR-3182 & 16 & 2.601167475 & 0.0001489232 \\
\hline hsa-miR-1976 & 1 & 2.400666849 & 0.0000026920 \\
\hline \multicolumn{4}{|c|}{ Downregulated miRNA } \\
\hline hsa-miR-155 & 21 & 0.442529258 & 0.0486285773 \\
\hline hsa-miR-30c & 1 & 0.4376255 & 0.0456339634 \\
\hline hsa-miR-148a & 7 & 0.433821762 & 0.0433979100 \\
\hline hsa-miR-320d & 13 & 0.423355394 & 0.0376287918 \\
\hline hsa-miR-193b & 16 & 0.411037164 & 0.0315374022 \\
\hline hsa-miR-3142 & 5 & 0.407958238 & 0.0301288756 \\
\hline hsa-miR-125a-5p & 19 & 0.407900215 & 0.0301027596 \\
\hline hsa-miR-548e & 10 & 0.403739023 & 0.0282706529 \\
\hline hsa-miR-377 & 14 & 0.403452896 & 0.0281476142 \\
\hline hsa-miR-181a & 9 & 0.39171302 & 0.0234167522 \\
\hline hsa-miR-9 & 1 & 0.383712109 & 0.0205353941 \\
\hline hsa-miR-136 & 14 & 0.376078245 & 0.0180319907 \\
\hline hsa-miR-30e & 1 & 0.356125342 & 0.0125381209 \\
\hline hsa-miR-320a & 8 & 0.355034273 & 0.0122785570 \\
\hline hsa-miR-181d & 19 & 0.344328059 & 0.0099380745 \\
\hline hsa-miR-664* & 1 & 0.334818122 & 0.0081545737 \\
\hline hsa-miR-335 & 7 & 0.327739702 & 0.0069927283 \\
\hline hsa-miR-127-3p & 14 & 0.324579351 & 0.0065166949 \\
\hline hsa-miR-153 & 2 & 0.315892956 & 0.0053352003 \\
\hline hsa-miR-30b & 8 & 0.289593177 & 0.0027367749 \\
\hline hsa-miR-29b & 1 & 0.283806256 & 0.0023302278 \\
\hline hsa-miR-23b & 9 & 0.279436815 & 0.0020562097 \\
\hline hsa-miR-29a & 7 & 0.276089317 & 0.0018641339 \\
\hline hsa-miR-3651 & 9 & 0.2701373 & 0.0015580967 \\
\hline hsa-miR-125b & 11 & 0.25515444 & 0.0009625090 \\
\hline hsa-miR-150 & 19 & 0.245821776 & 0.0006960970 \\
\hline hsa-miR-129* & 7 & 0.202755244 & 0.0001156061 \\
\hline hsa-miR-3647-3p & 16 & 0.201213328 & 0.0001072185 \\
\hline hsa-miR-124 & 8 & 0.159268752 & 0.0000091529 \\
\hline hsa-miR-3607-5p & 5 & 0.156882099 & 0.0000077280 \\
\hline hsa-miR-3653 & 22 & 0.150251473 & 0.0000047301 \\
\hline hsa-miR-9* & 5 & 0.149422405 & 0.0000044385 \\
\hline hsa-miR-3607-3p & 5 & 0.078787431 & 0.0000000009 \\
\hline
\end{tabular}




\section{SP cells exhibit drug resistance}

To determine whether classical or novel clinically active agents mediate SP cell viability, SP or MP cells were treated with anti-myeloma drugs bortezomib, $\mathrm{As}_{2} \mathrm{O}_{3}$, dexamethasone, melphalan, or doxorubicin with increasing concentrations for 24 and 48 hours. Cell viability was then measured by CCK8 assays. As shown in Fig. 2A, active agents significantly decreased the viability of SP and MP cells in a time- and dose-dependent manner. We observed at least two-fold a half-maximal inhibitory concentration (IC50) concentration in inhibitory rates of SP cells compared to MP cells in all test drugs. This may be one of the obvious triggers for relapse, since conventional treatment fails to affect the active stem-like MM cells.

To determine the effects of these agents on reducing the number of SP cells, we assessed the SP and MP fraction after 48 hour treatment with the various drugs. We found that $\mathrm{As}_{2} \mathrm{O}_{3}$ and melphalan could significantly decrease the percentage of SP cells. However, in contrast to Nara's study, which may be due to the different myeloma cell type, bortezomib only slightly reduced SP fraction even in relatively high concentrations (Fig. 2B) [8]. Dexamethasone and doxorubicin did not affect SP cells. All these drugs decreased MP fraction compared to control.

We next evaluated the effect of the drugs on growth of SP cells. Similar results from NCI-H929 and KMS11 SP and MP cells were obtained. Approximately 50\% decrease in colony number and formation were observed in presence of bortezomib and $\mathrm{As}_{2} \mathrm{O}_{3}$, while nearly no colony formation in cells treated with melphalan (Fig. $2 \mathrm{C})$. These results indicate that these drugs hampered growth of potential SP cells, whereas SP and MP cells was unchanged by treatment with dexamethasone or doxorubicin.

Subsequently, we evaluated the effects of the drugs on the SP cell cycle. None of the drugs altered the cell cycle distribution in SP cells compared to controls (data not shown). Apoptosis by using annexin V-binding assay in $\mathrm{SP}$ cells treated by bortezomib, $\mathrm{As}_{2} \mathrm{O}_{3}$, or melphalan increased dramatically in a time- and dose-dependent manner, whereas dexamethasone or doxorubicin treatment failed to induce apoptosis in SP cells (Fig. 2D). Therefore, we speculated that the ability of bortezomib, $\mathrm{As}_{2} \mathrm{O}_{3}$, or melphalan to decrease clonogenicity to confer drug resistance in SP cells was derived from apoptosis.

\section{SP cells showed the potential distinct miRNA expression pattern}

We performed MiRCURYTM LNA array analysis of sorted SP and MP cells from two relapsed myeloma patients with more than $70 \%$ bone marrow plasma cells from bone marrow smear. Among the miRNAs exhibiting at least two-fold and statistically significant difference ( $p$ $<0.05$ ) in expression, 43 miRNAs were identified in total. Ten of which were upregulated and 33 were downregulated in SP cells compared with those in MP cells (Table 1). Of these potential distinct miRNA expression pattern, miR451 , miR-144 and miR-150, were of interest because they have been reported to be involved in pathological mechanism of CSCs $[20,21]$. The expression of these three miRNAs were further confirmed by qRT-PCR based on $2^{-\Delta \Delta \mathrm{Ct}}$ methods (Fig. 3).

\section{Differential expression of miRNAs regulated PI3K/Akt/mTOR signaling pathways in SP cells}

It is well known that genes do not work in isolation. Instead, complex molecular networks and cellular pathways are often involved in disease pathogenesis [22, 23]. We therefore performed pathway analysis of the predicted targets using KEGG to define the biological networks affected by differentially expressed miRNAs and their targets in SP cells. The list of the top pathways highly related to SP cells ranked by the enrichment $p<$ 0.005 is presented in Supplemental Table 1 (FDR $<0.05$ ). Out of all these pathways, which have been successively reported to play a determinant role in CSCs, PI3K/Akt/ mTOR signaling appears to act as a crucial pathway in disease progression and development of therapeutic resistance $[24,25]$. However, the role of PI3K/Akt/ mTOR signaling in the maintenance of myeloma CSCs has not been clarified. We next confirmed the fidelity and reliability of the representative target genes located in PI3K/Akt/mTOR pathway by western blot analysis. Our results showed PI3K/Akt/mTOR proteins, p-S6 and p-P70S6K, to be significantly upregulated in SP cells compared with those of MP cells (Supplemental Fig. 2). Therefore, we speculated that PI3K/Akt/mTOR pathway may be regulated by specific miRNAs to exert its biological effects in MM SP cells.

\section{miR-451 enhanced the potentiated drug synergism effect in SP cell}

To evaluate whether any of the 43 aberrantly expressed miRNAs previously identified in SP cells could target the core regulators in $\mathrm{PI} 3 \mathrm{~K} / \mathrm{Akt} / \mathrm{mTOR}$, we used computational methods to predict the TSC1 and $C A B 39$ which might be targeted by miR-451, expression in this pathway. Notably, miR-451 has been previously confirmed to be upregulated in SP cells (Fig. 3) and shown to maintain CSC properties in other diseases [21]. To examine the effects of miR-451 in MM SP cells, qRTPCR confirmed a remarkable downregulation of miR-451 expression in SP cells after transfection of the mature sequence of miR-451 inhibitor (miR-451-inh) at $100 \mathrm{nM}$ (Supplemental Fig. 3). 
A

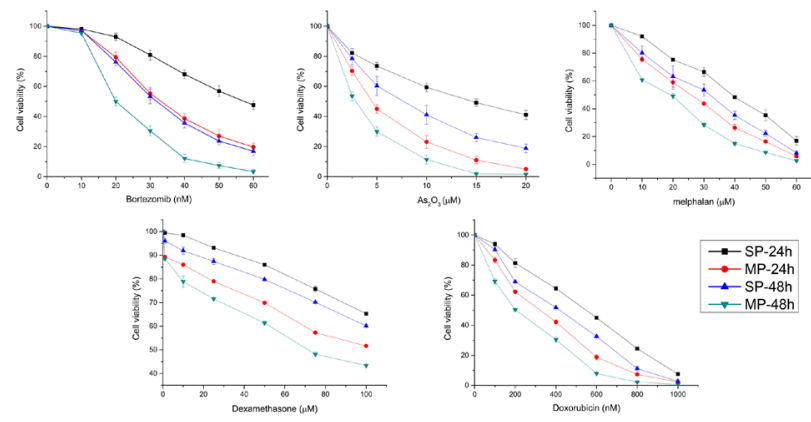

B

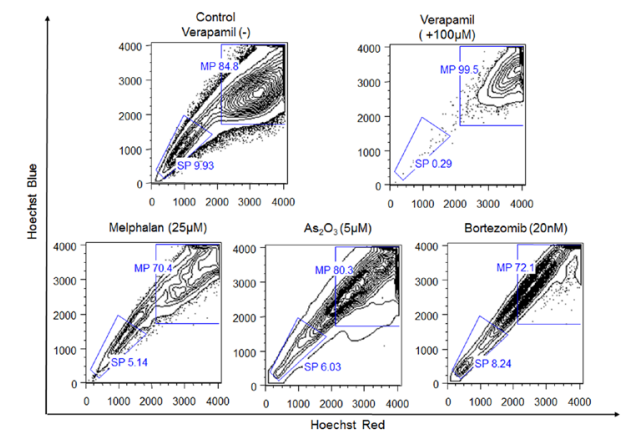

C
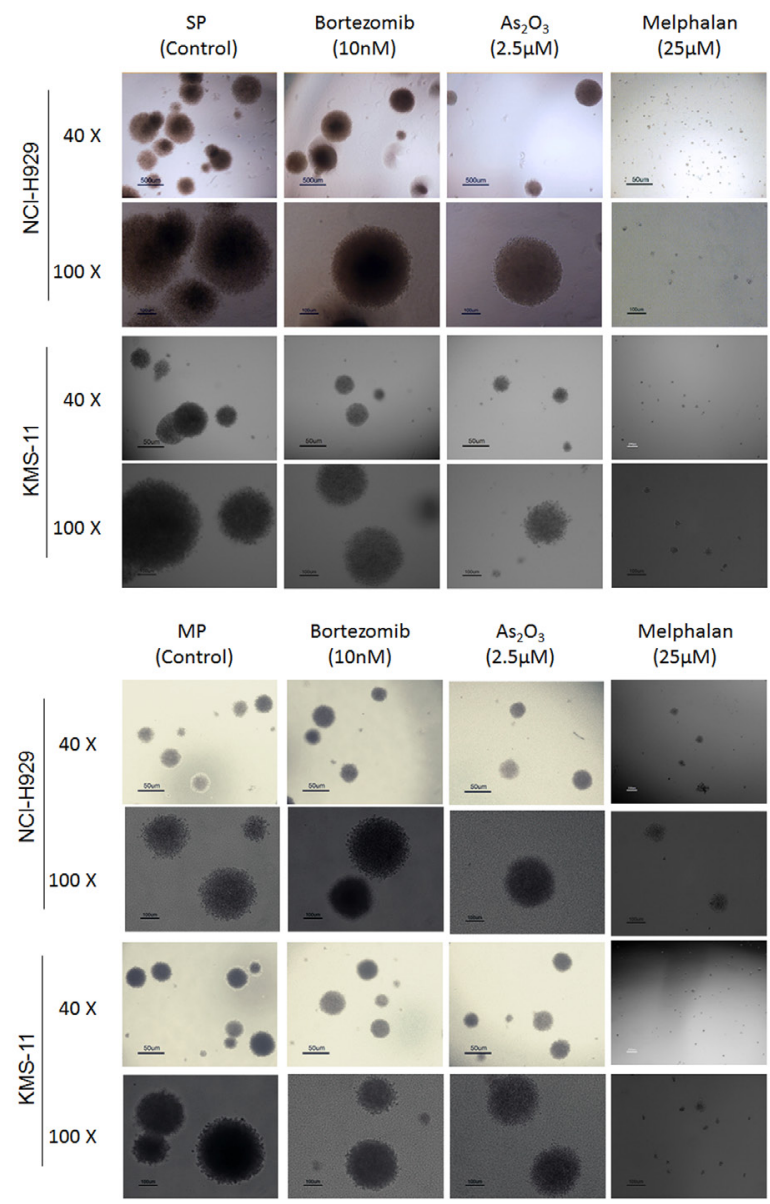


\section{D}

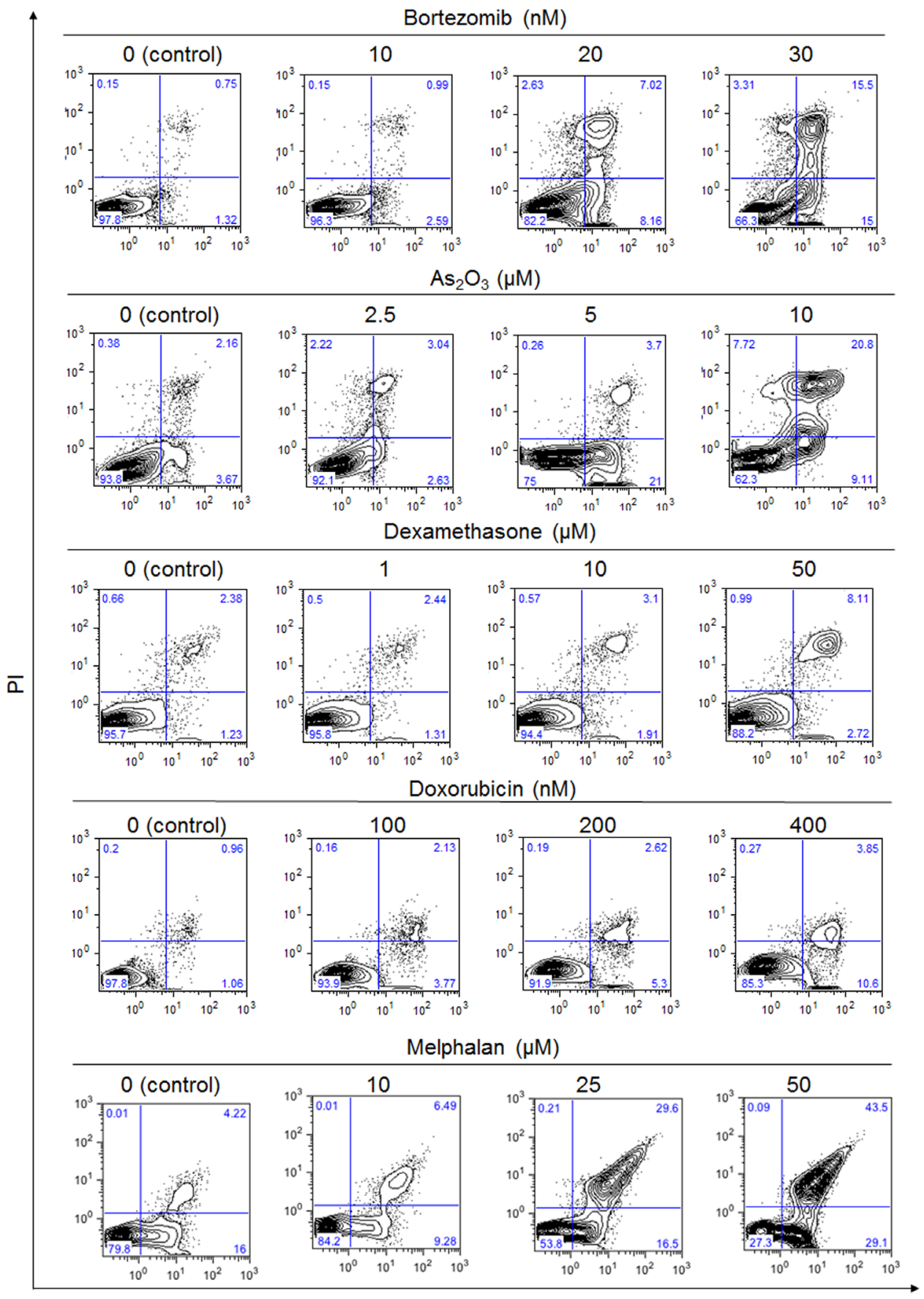

ANNEX V-FITC

Figure 2: SP cells are resistant to chemotherapy agents. A. Classical or novel clinically active agents: bortezomib, $\mathrm{As}_{2} \mathrm{O}_{3}$, dexamethasone, melphalan, or doxorubicin mediate NCI-H929 SP cell viability for 24 and 48 hours as measured by CCK-8 assay. B. Percentage of SP and MP fraction in KMS-11 cells after treating with melphalan, $\mathrm{As}_{2} \mathrm{O}_{3}$, and bortezomib for 48 hours. Cells disappeared with verapamil treated at $100 \mu \mathrm{M}$ as control. C. CFC assay showed the effect of bortezomib, $\mathrm{As}_{2} \mathrm{O}_{3}$, melphalan on SP and MP cells from NCI-H929 and KMS-11 cell lines. $(200$ cells/plate, magnification $40 \times, 100 \times$ ). D. SP cells from NCI-H929 cell line were treated with bortezomib, $\mathrm{As}_{2} \mathrm{O}_{3}$, dexamethasone, melphalan, or doxorubicin for 48 hours, and apoptosis was measured with Annexin V/PI binding assay by flow cytometry. A representative graph from 3 independent experiments is shown $(p<0.05 ; \mathrm{n}=3)$. 
Unexpectedly there was no difference in cell proliferation, apoptosis, cell cycle status, or clonogenicity between SP and MP cells from NCI-H929 and KMS11 at any time point after transfection of miR-451-inh oligonucleotides (data not shown). Intriguingly, miR-451 might have a potential anti-myeloma SP cell synergistic effect against CSC characteristics with bortezomib, $\mathrm{As}_{2} \mathrm{O}_{3}$, and melphalan treatments when SP cells were transduced with miR-451 inhibitor. Similar results were observed from NCI-H929 and KMS-11 cell lines for after 48 hour treatment. Representative NCI-H929 SP cells results are shown in Figure 4. In apoptosis assay, SP cells transfected with miR-451-inh showed a significant increase in apoptosis compared to treatment with each agent alone, indicating that the reduced levels of miR-451 enhanced the efficiency of bortezomib, $\mathrm{As}_{2} \mathrm{O}_{3}$, or melphalan on SP cells (Fig. 4A, $p<0.05$ ). Similarly, combination of miR451-inh with anti-myeloma drugs significantly decreased colony formation compared to treatment with each agent alone, indicating that the low levels of miR-451 restrained SP cell proliferation (Fig. 4B, $p<0.05$ ).

One of the underlying mechanisms for such drug synergism effect might be associated with $\mathrm{ABC}$ transporters. As shown in Fig. 4C, qRT-PCR data shows a near $50 \%$ decrease of ABCB1 in sorted SP cells after treatment with miR-451-inh compared to controls. Only slight changes were detected in $\mathrm{ABCG} 2, \mathrm{ABCC} 2$ and ABCC4 mRNA expression of SP cells (Supplemental Fig. 4). These results suggests that miR-451 enhanced the drug synergistic effect in SP cells might contribute to affect the $\mathrm{ABC}$ transporter pump function by regulating its family, especially in ABCB1, but further function research is needed to confirm this result.

\section{miR-451 targeted TSC1 gene to regulate PIK3/ Akt/mTOR signaling in SP cells}

The putative corresponding target TSC1 was of particular interest due to its known function in a wide array of cellular processes through negative control of mTORC1 involving the $\mathrm{PIK} 3 / \mathrm{Akt} / \mathrm{mTOR}$ regulation. To evaluate whether abnormally expressed miR-451 could target $T S C 1$, which has a highly conserved binding site in the 3'UTR of TSC1 predicted by miRanda, and TargetScan, a luciferase reporter assay was used to study. The activity of TSC1 luciferase was blocked by overexpression of miR-451 compared with control. This was abrogated by mutation at the miR-451 binding site, demonstrating a direct effect of miR-451 on the 3'UTR of TSC1 (Fig. $5 \mathrm{~A})$. Furthermore, inhibition of miR-451 led to an increase in transcription and translation of TSC1 in SP cells (Fig. $5 \mathrm{~B}$ and $5 \mathrm{C}$ ). Moreover, inhibition of miR-451 reduced downstream effectors, phospho-S6 and phospho-4EBP1, by inhibiting PIK3/AKT/mTOR signaling pathway in SP cells (Fig. 5D).

\section{A novel mTOR inhibitor agent $\mathrm{S} 14161$ targets MM SP cells specificity}

From the results so far, it is clear that the PIK3/ Akt/mTOR pathway may be important for maintaining $\mathrm{SP}$ cell features. To confirm this, we examined the effect of inhibiting PIK3/Akt/mTOR pathway on SP cells. Rapamycin, a specific classical inhibitor of mTOR, was firstly tested for its ability to reduce the SP fraction in NCI-H929 cells. Treatment with rapamycin at $5 \mu \mathrm{M}$ for three days, resulted in a significant decrease in SP fraction, from $1.54 \%$ to $0.28 \%$ (Supplemental Fig. 5). Recently, a small chemical compound, S14161, was identified as a PI3K inhibitor. S14161 displayed no gross toxicity at concentrations up to $500 \mathrm{mg} / \mathrm{kg}$ in vivo, making it a good candidate for use in myeloma and leukemia treatment in preclinical activity [26]. Thus, we were in particular interested in testing S14161 against SP cells. As shown in Fig. 6A, S14161 drastically reduced the SP fraction within NCI-H929 cells in a dose-dependent manner after 72-hour treatment. The ability of the S14161 to decrease the SP fraction was at least partially due to its ability to preferentially inhibit the SP cells. To support this, we treated NCI-H929 SP and MP cells with S14161 $(0 \sim 12.5 \mu \mathrm{M})$ for 24 and 48 hours and evaluated MM cell viability using CCK-8 assay. The SP cells treated for 24
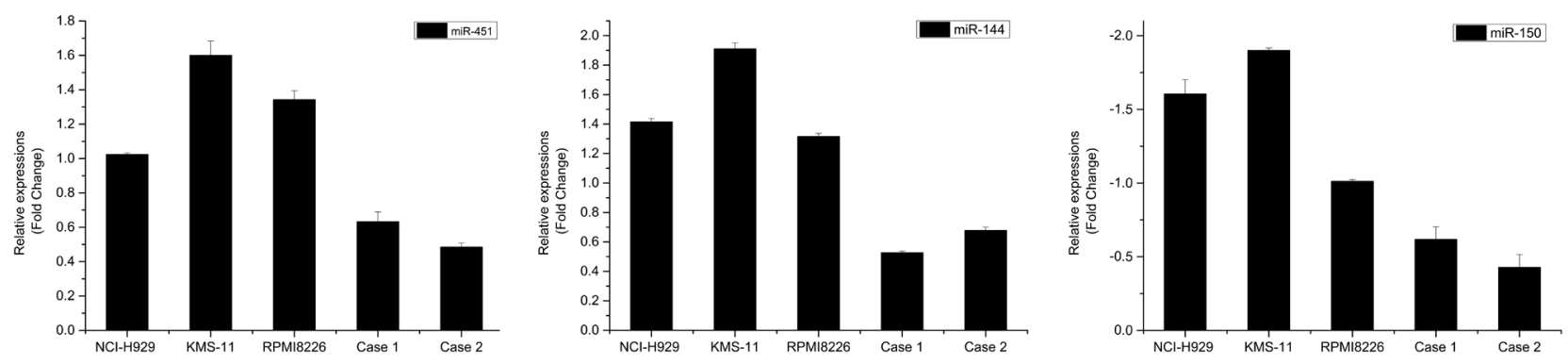

Figure 3: qRT-PCR validation of miRNA expression in SP cells. The column indicates the relative fold change compared to MP cells. Each sample was analyzed in triplicate and was normalized to U6. Fold change was calculated by $2^{-\Delta \Delta C t}$ method. The results were consistent with the microarray data. 
hours had IC50 $<7.0 \mu \mathrm{M}$, which were higher than MP cell lines (Fig. 6B). We further observed that SP cells after treatment with $2.5 \sim 7.5 \mu \mathrm{M} \mathrm{S} 14161$ for 24 or 48 hours, showed increased apoptosis rate in a time- and dose-dependent manner (Fig. 6C). In addition, S14161 dramatically reduced the colony forming capacity of SP cells in comparison to control (Fig. 6D). Because S14161 decreased levels of D-cyclins, we tested the effects of S14161 on cell-cycle progression. In contrast to previous report [26] and MP cells data from our study (not shown), we measured that $\mathrm{S} 14161$ at $5 \mu \mathrm{M}$ induced SP cell cycle arrest at $\mathrm{G} 2 / \mathrm{M}$ phase, with a corresponding reduction in the number of G0 quiescent cells in a time-dependent manner (Fig. 6E), which might be mediated others mechanism to effect cell cycle on SP cells. Furthermore, S14161 exhibited synergistic apoptotic effect when administered in conjunction with miR-451 (Fig. 6F).
Taken together, the effect of the PI3K inhibitor S14161 in SP cells and the synergistic activity with the miR-451 inhibitor support the notion that S14161 may have potent activity not only in myeloma cells also in MM SP cells.

\section{DISCUSSION}

Although there are several viewpoints on the stemlike properties within MM cells, the definitive MM CSCs phenotype/markers are still under investigation [27]. In this study, we used the efflux of Hoechst dye to identify the SP phenotype and isolate MM cancer stem-like cells.

We first identified SP cells which remained consistently a small between various experiments and over a panel of myeloma cells. As expected, no distinctive phenotypic features were identified between SP and MP cells. Consistent with previous studies [5,

A

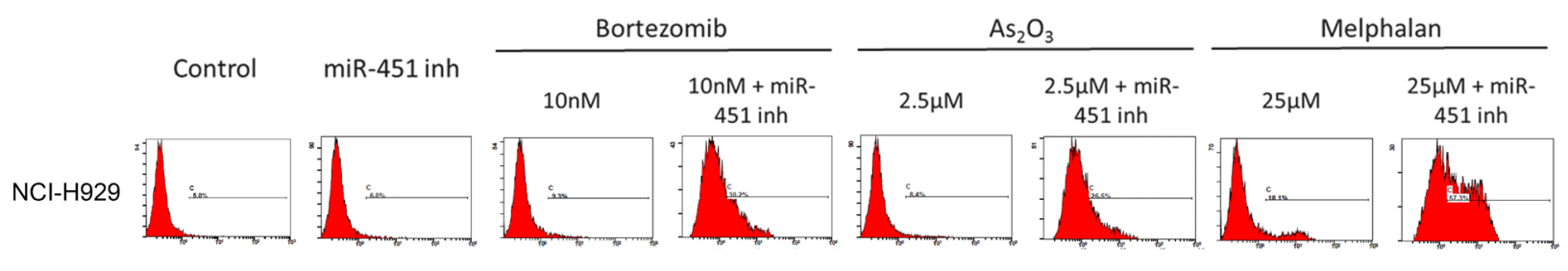

B

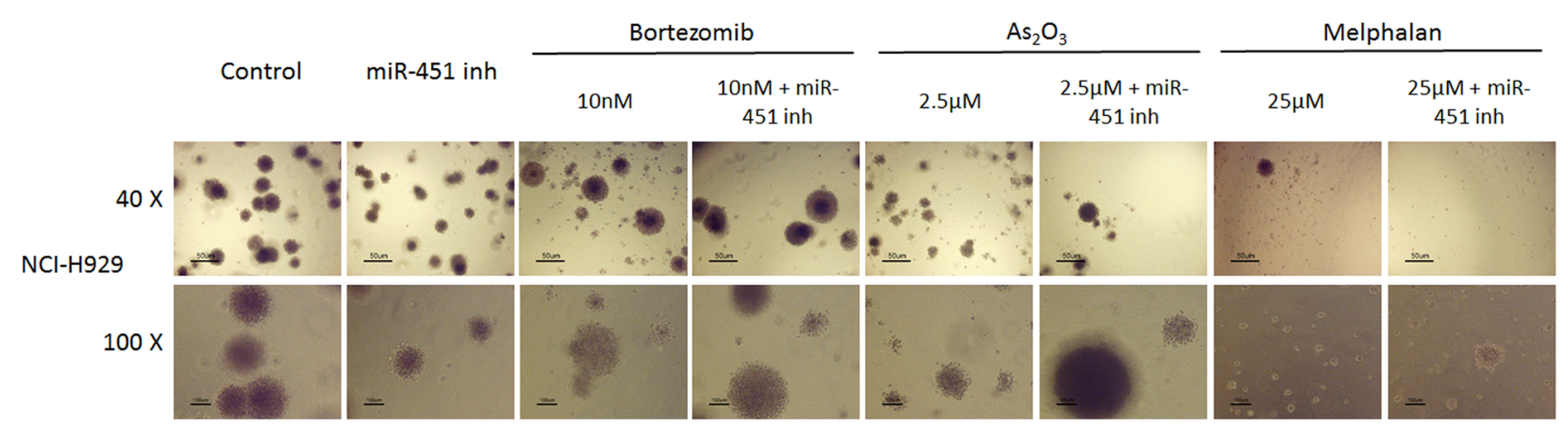

C

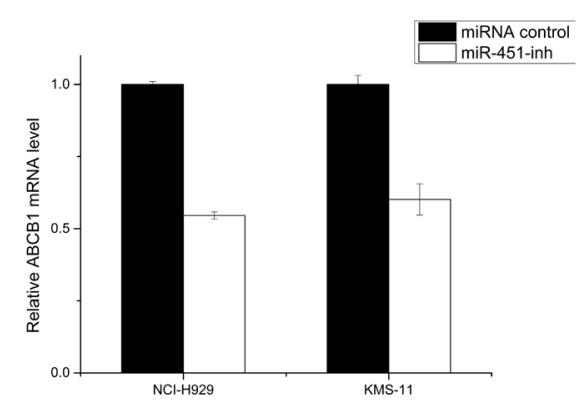

Figure 4: The potentiated drug synergistic effect of reducing miR-451 expression on SP cells. A. Cell apoptosis was detected in SP cells from NCI-H929 cell line transfected with miR-451-inh treated with bortezomib, $\mathrm{As}_{2} \mathrm{O}_{3}$, and melphalan by flow cytometry. B. The clonogenic capacity was determined in SP cells from NCI-H929 cell line transfected with miR-451-inh treated with bortezomib, As $\mathrm{O}_{3}$, and melphalan (400 cells/plate, magnification 40× and 100×). C. qRT-PCR showing relative MDR1 mRNA levels in NCI-H929 and KMS-11 SP cells transfected with miR-451-inh compared to control. 
10, 13], we observed CSC properties (i.e. cell cycle status, clonogenicity, and high drug efflux capacity) in SP cells. In cell cycle analysis, SP cells contain larger percentage of quiescent population than MP cells, which may be one of the reasons for the SP-induced drug resistance. Furthermore, we confirmed that SP cells contain clonogenic cells with high proliferative ability, a distinguished property of CSCs for producing lessdifferentiated progeny and undergoing self-renewal [5], resulting in generation of a significant proportion of cells in comparison with MP cells. Although the proliferation rates were low compared to others reports $[8,13]$, it might be due to the low amount of SP cells used per plate for colony formation assay. Moreover, we still observed a significantly higher tumorigenicity in SP cells compared to MP cells through our in vitro experiments and in vivo

A

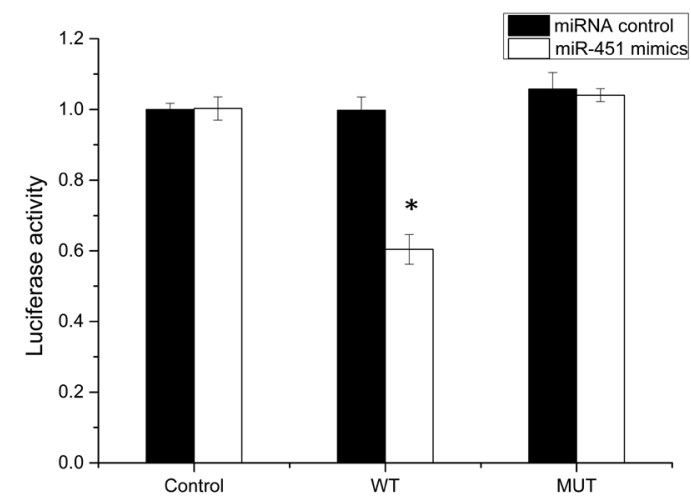

C

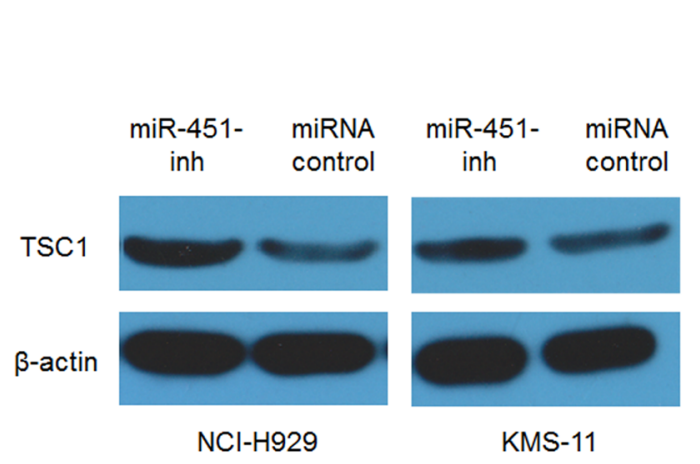

study of SP cell tumorigenicity, though with limited data due to the rare numbers of SP cells from FACS. Combined with previous studies [5, 13], we have generated a solid foundation in confirming SP cells as a source of tumorigenicity of myeloma for CSC studies.

Many studies have demonstrated CSCs as an important cause of drug resistance and relapse due to their regulation of $\mathrm{ABC}$ activity in drug efflux [5, 10, 13]. Similarly, we observed an elevated expression of ABCG2 in SP cells, confirming ABCG2 as a molecular marker of SP phenotype [18]. We also observed high levels of ALDH activity in SP cells, which has been previously shown to also be high in myeloma stem-like cells [5, 28]. However, ALDH was not an eligible marker for myeloma CSCs in our study since over $50 \%$ of SP cells fail to meet the criteria for being defined as CSCs.

\section{B}

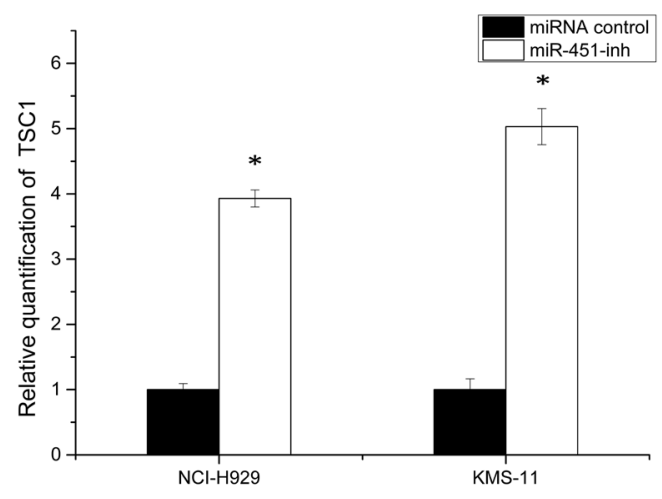

D

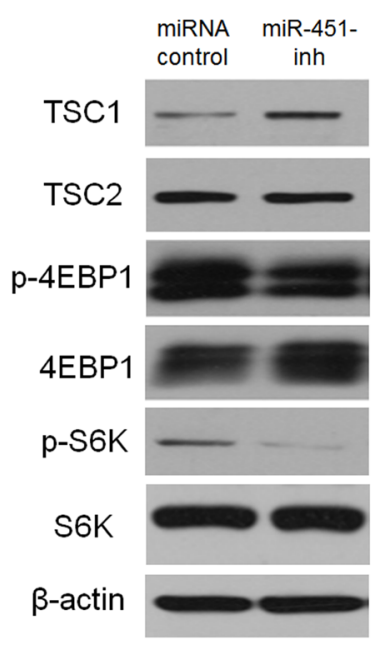

Figure 5: Identification and analysis of TSC1 as a target gene of the miR-451. A. Direct targeting of TSC1 3'UTR by miR-451. NCI-H929 cells were co-transfected with luciferase/TSC1 3'UTR reporter vector (WT) and miRNA negative control or miR-451-mimics. A reporter vector with a mutated miR-451-binding site in the TSC1 3'UTR (MUT) was used as a control. Luciferase levels are expressed as mean relative to controls $\pm \mathrm{SD}$; ${ }^{*} p<0.05$. Relative quantitation of TSC1, using qRT-PCR B. and western blot analysis C. in NCI-H929 SP cells following transfection with the miR-451 inhibitor $\left({ }^{*} p<0.05\right)$. D. Inhibition miR-451 expression to further block PIK3/AKT/mTOR signaling activity in NCI-H929 SP cells. 

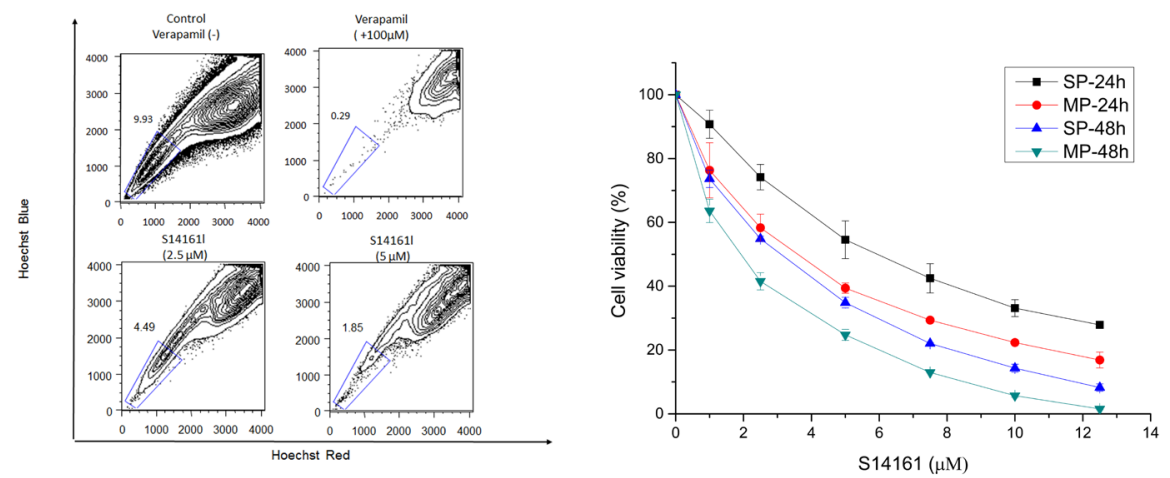

C

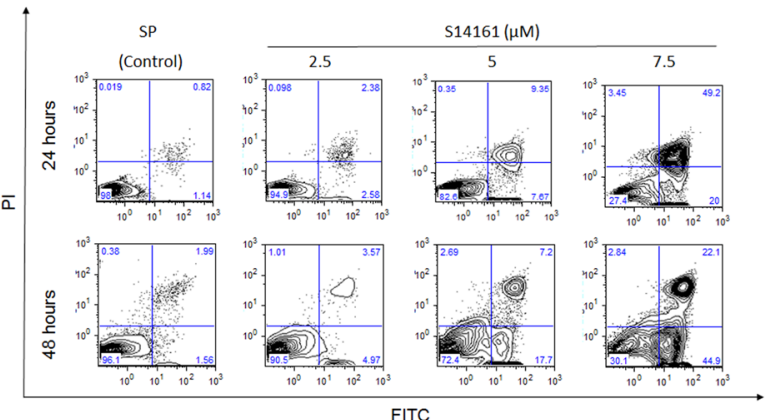

D

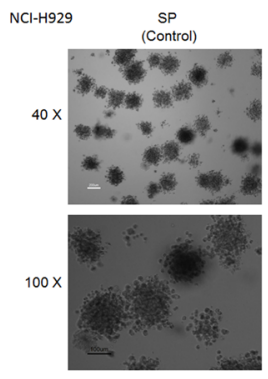

$\mathbf{F}$

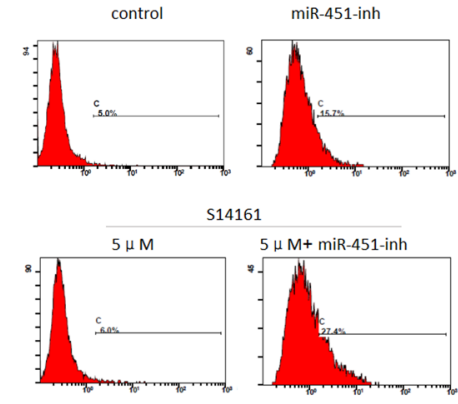

E

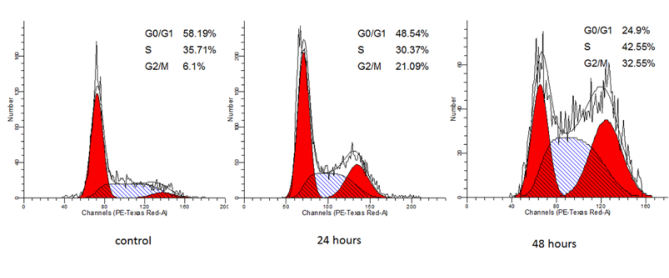

G

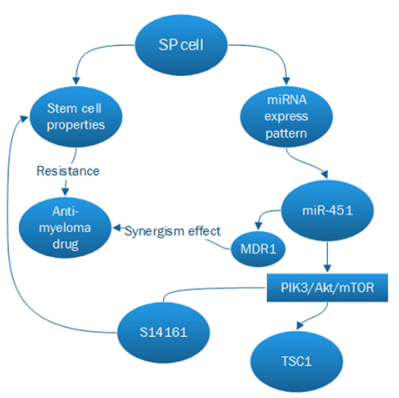

Figure 6: A novel mTOR inhibitor agent S14161 regulates SP cells stem cell properties. A. S14161 decreased the percentage of SP fraction in NCI-H929 cells with a dose-dependent manner at 72 hours and cells treated with verapamil (100 $\mu \mathrm{M})$ as the negative control. B. S14161 mediated NCI-H929 SP cell validity for 24 and 48 hours measured by CCK-8 assay. C. SP cells from NCI-H929 cell were treated with S14161 for 24 or 48 hours, and apoptosis was measured with Annexin V/PI binding assay by flow cytometry. D. CFC assay shows the effect of S14161 on SP cells from NCI-H929 cell line. (600 cells/plate, magnification $40 \times, 100 \times)$. E. S14161 induced SP cell cycle from G0 to G2/M phase in a time-dependent manner. F. SP cells treated with S14161 and inhibiting mir-451 expression prompt apoptosis by flow cytometry. Representative graph from 3 independent experiments is shown $(p<0.05 ; \mathrm{n}=3)$. G. The model of this study hypothesis shows potential mechanisms by which miRNA regulates biologic relevance in MM SP cells through PIK3/Akt/mTOR signaling. 
The CSC hypothesis states that a small subset of cells with in a cancer population is intrinsically more resistant to therapy than the rest of the tumor cells [6]. Previous studies have reported CD138-/CD19+/CD20+/ CD27+ MM stem cells to be resistant to dexamethasone, lenalidomide, cyclophosphamide and bortezomib [5]. However, in other studies, MM SP cells were susceptible to lenalidomide [13] or bortezomib treatment [8]. Here we expanded the drug resistance analysis to a panel of active clinical agents and showed that SP cells were more resistant to bortezomib, $\mathrm{As}_{2} \mathrm{O}_{3}$, dexamethasone, melphalan, and doxorubicin compared to MP cells. Notably, we show SP cells to be susceptible to bortezomib, $\mathrm{As}_{2} \mathrm{O}_{3}$, and melphalan treatment as seen from the decreased SP fraction, significantly increased SP cells apoptosis, as well as the lowered percentage of SP population and clonogenicity at clinically achievable concentrations.

To the best of our knowledge, this is the first study to characterize and compare miRNA signatures of MM SP cells with MP cells. Of the abnormally regulated miRNAs, we looked at the molecular mechanisms involved in miR451-mediated effects. Cells expressing miR-451 has been demonstrated to exhibit CSCs properties in colon carcinoma [21, 29]. Although miR-451 has yet been proven directly effective against myeloma SP cells in proliferation, apoptosis, or self-renewal, we found miR451 to potentiate the effects of bortizomib, $\mathrm{As}_{2} \mathrm{O}_{3}$, and melphalan through enhancing apoptosis and inhibit clonal sphere formation in SP cells.

We further found that treatment with miR-451 inhibitor decreased the expression of MDR1 mRNA expression in MM SP cells, which may confer its synergistic effects. Previous study reported that miR-451 increased MDR1 expression in parental cell line A2780 [30]. Taken together, our results suggests that the effects of miR-451 on MDR1 expression appear to modulate antimyeloma agents' effectiveness by inhibiting the expression of certain transcriptional factors involved in suppressing MDR1 gene activation. The precise mechanisms require further investigation.

Until now, several pathways, such as the hedgehog [10] and Notch pathways [6], have been shown to be involved with maintaining myeloma stem cell properties. The role of $\mathrm{PI} 3 \mathrm{~K} / \mathrm{Akt} / \mathrm{mTOR}$ signaling in the maintenance of CSCs has been addressed in other tumors, but the conclusions of these reports are controversial [25, 31]. We identified the effects of miR-451 on the activation of the PI3K/Akt/mTOR pathway and its downstream targets to stimulate stemness features through direct targeting of TSC1. Disruption of PI3K/Akt/mTOR signaling by constitutive miR-451 expression alters the activity of pathways downstream of TSC1, including reduced S6 and 4EBP1 phosphorylation. Thus, miR-451 targets TSC1 to mediate $\mathrm{PI} 3 \mathrm{~K} / \mathrm{Akt} / \mathrm{mTOR}$ signaling, which plays an essential role in myeloma stem cell biology.

A novel specific inhibitor, S14161, inhibits
D-cyclin transactivation via the PI3K signaling pathway to exert anti-myeloma activity [26], while displaying no gross toxicity at concentrations up to $500 \mathrm{mg} / \mathrm{kg}$ in an in vivo assay, making it a probable drug candidate. More importantly for myeloma SP cells, S14161 exerted multiple actions including directly decreasing SP fraction, inhibiting SP proliferation, increasing apoptosis, inducing cell cycle progression, as well as synergizing with low miR-451 expression. Taken together, these suggest a significant potential target for myeloma stem and cancer cell therapeutics. The overexpression of D-cyclins contributes to the pathogenesis and chemoresistance of MM [32]. Our previous studies have demonstrated the ABCG2 activity of SP cells and the MDR1 mediated miR-451 effects. Collectively, we believe that S14161 may down-regulate D-cyclins via a MDR pathway mediated by ABCG2 or MDR1, which controls or bypasses these events to affect SP features.

In summary, our results demonstrate that MM SP cells exhibit stemness, and the PI3K/Akt/mTOR pathway is activated in SP cells. Regulating TSC1 expression by miR-451 and related downstream targets (Fig. 6G) may be relevant to the pathophysiology of the disease, and miR451 may serve as a potential therapeutic target.

\section{MATERIALS AND METHODS}

\section{Culture of MM cell lines and primary MM cells}

A panel of myeloma cell lines NCI-H929, RPMI 8226, KMS-11, LP-1, U266, SKO, and primary myeloma cells were used, which were cultured as described in supplemental Methods.

\section{Drug, reagents and antibodies}

Bortezomib was kindly provided by XianJanssen Pharmaceutical Ltd. Rapamycin (Sirolimus) was purchased from Selleck Chemicals LLC (Houston, TX, USA). 8-ethoxy-2-(4-fluorophenyl)-3-nitro-2Hchromene (S14161) was kind provided by Dr. Mao (Cyrus Tang Hematology Center, Soochow University, Suzhou, Jiangsu, China) [26]. Other chemicals were purchased from Sigma Company (Saint Louis, MO), unless specifically annotated. PI3K/Akt/mTOR pathway related primary antibodies were purchased from Abcam (Cambridge, MA, USA), and others primary antibodies were purchased from Cell Signaling Technology (Danvers, MA, USA). 


\section{Flow cytometric analysis}

SP sorting analysis was performed with Hoechst 33342 dye method as described by Goodell et al. [9] with modifications. Aldehyde dehydrogenase (ALDH) activity was tested by the Aldefluor reagent (Stem Cell Technologies, Vancouver, Canada). Cell apoptosis assay was detected by using annexin V-binding assay, and immunophenotyping study was performed with mouse anti-human related antibodies. These methods were described in detail in Supplemental Methods.

\section{MiRNA profiling and analysis}

To screen the miRNAs profiling between SP and MP cells, miRCURYTM LNA Array (v.16.0, Exiqon) was used according to the manufacturer's instructions, as described in the Supplemental Methods. The microarray data were deposited on the Gene Expression Omnibus (accession number GSE56163).

\section{Bioinformatic analysis based on miRNA expression profile}

MiRNA target was predicted by miRanda, and TargetScan, as well as the miRNA analysis involved generation of pathway networks using the Kyoto Encyclopedia of Genes and Genomes (KEGG), as described in supplemental Methods.

\section{Quantitative real-time PCR assay (qRT-PCR)}

qRT-PCR was performed using the quantitative SYBR Green PCR kit following the manufacturer's protocol, as described in Supplemental Methods. All quantitative the fold change was calculated by the $2^{-\Delta \Delta \mathrm{Ct}}$ method.

\section{RNA oligonucleotide and cell transfection}

MiRNA mimics, miRNA inhibitors, and their cognate control RNAs were purchased from Ambion (Austin, TX, USA) or Genepharma (Shanghai, China). Transfection was performed using SuperFection (Pufei, USA) transfection reagent according to the manufacturer's instructions. Transfection efficiency $(>90 \%)$ was confirmed with the use of the Silencer 6-carboxy-fluorescine (FAM)-labeled Negative Control.

\section{Cell-based assays}

Cell viability was tested by colorimetric assay kit (Dojindo Laboratories, Tokyo, Japan) based on the MTT assay. Clonogenicity activity was detected by colonyforming cell (CFC) assay. Both methods were described in detail in Supplemental Methods.

\section{Western blot analysis}

Cell lysates and total protein concentration were measured with the BCA Protein Assay Kit (Pierce Biotechnology, Rockford IL, USA). The proteins of interest were detected, as described in Supplemental Methods.

\section{Luciferase assay}

The luciferase activity was measured using the Dual-Luciferase Reporter Assay System (Promega), as described in Supplemental Methods.

\section{Animal models}

SP or MP cells from NCI-H929 cell lines were injected subcutaneously together with Matrigel basement membrane matrix (Becton Dickinson) into NOD/SCID mice approved in accordance with the institutional guidelines for the use of laboratory animals; details were described in Supplemental Methods.

\section{Statistical analysis}

Data were expressed as the mean plus or minus SD. Analysis of statistical significance between groups was made using a 2-tailed unpaired Student's t test. A value of $p<0.05$ was considered statistically significant. All experiments were performed in triplicate with consistent results.

\section{ACKNOWLEDGMENTS}

The authors would like to thank Dr. Wu Zhang from State Key Laboratory of Medical Genomics, Shanghai Institute of Hematology for technical support, Suping Zhang for editorial assistance, and appreciate Dr. Mao from Cyrus Tang Hematology Center, Soochow University in Suzhou for kind provide S14161 agent. This work was supported in part by National Natural Science Foundation of China (NFSC30900643, 81170500, 81372543), and Shanghai Pujiang Program (09PJ1400400).

\section{CONFLICTS OF INTEREST}

The authors declare that they have no competing interests. 


\section{AUTHORSHIP CONTRIBUTIONS}

J.D., S.L., J.H.: conception and design, provision of study material, collection and/or assembly of data, data analysis and interpretation, manuscript writing; J.H., R.L., J.F., H.X., W.F., C.Z.: experiment performing; collection and/or assembly of data; J.D., J.Y., J.H.: final approval of manuscript.

\section{REFERENCES}

1. Mahindra A, Hideshima T, Anderson KC. Multiple myeloma: biology of the disease. Blood Rev. 2010;24 Suppl $1:$ S5-11.

2. Tan D, Chng WJ, Chou T, Nawarawong W, Hwang SY, Chim CS, et al. Management of multiple myeloma in Asia: resource-stratified guidelines. Lancet Oncol. 2013;14:e57181.

3. Delude C. Tumorigenesis: Testing ground for cancer stem cells. Nature. 2011;480:S43-5.

4. Matsui W, Huff CA, Wang Q, Malehorn MT, Barber J, Tanhehco Y, et al. Characterization of clonogenic multiple myeloma cells. Blood. 2004;103:2332-6.

5. Matsui W, Wang Q, Barber JP, Brennan S, Smith BD, Borrello I, et al. Clonogenic multiple myeloma progenitors, stem cell properties, and drug resistance. Cancer Res. 2008;68:190-7.

6. Boucher K, Parquet N, Widen R, Shain K, Baz R, Alsina M, et al. Stemness of B-cell progenitors in multiple myeloma bone marrow. Clin Cancer Res. 2012;18:6155-68.

7. Kim D, Park CY, Medeiros BC, Weissman IL. CD19-CD45 low/- CD38 high/CD138+ plasma cells enrich for human tumorigenic myeloma cells. Leukemia. 2012;26:2530-7.

8. Nara M, Teshima $K$, Watanabe A, Ito $M$, Iwamoto $K$, Kitabayashi A, et al. Bortezomib reduces the tumorigenicity of multiple myeloma via downregulation of upregulated targets in clonogenic side population cells. PLoS One. 2013;8:e56954.

9. Goodell MA, Brose K, Paradis G, Conner AS, Mulligan RC. Isolation and functional properties of murine hematopoietic stem cells that are replicating in vivo. J Exp Med. 1996;183:1797-806.

10. Peacock CD, Wang Q, Gesell GS, Corcoran-Schwartz IM, Jones E, Kim J, et al. Hedgehog signaling maintains a tumor stem cell compartment in multiple myeloma. Proc Natl Acad Sci U S A. 2007;104:4048-53.

11. Huff CA, Matsui W. Multiple myeloma cancer stem cells. J Clin Oncol. 2008;26:2895-900.

12. Loh YS, Mo S, Brown RD, Yamagishi T, Yang S, Joshua DE, et al. Presence of Hoechst low side populations in multiple myeloma. Leuk Lymphoma. 2008;49:1813-6.

13. Jakubikova J, Adamia S, Kost-Alimova M, Klippel S, Cervi D, Daley JF, et al. Lenalidomide targets clonogenic side population in multiple myeloma: pathophysiologic and clinical implications. Blood. 2011;117:4409-19.

14. Bartel DP. MicroRNAs: target recognition and regulatory functions. Cell. 2009;136:215-33.

15. Sun K, Lai EC. Adult-specific functions of animal microRNAs. Nat Rev Genet. 2013;14:535-48.

16. Bhardwaj A, Arora S, Prajapati VK, Singh S, Singh AP. Cancer "Stemness"- Regulating MicroRNAs: Role, Mechanisms and Therapeutic Potential. Curr Drug Targets. 2013;14:1175-84.

17. Inui M, Martello G, Piccolo S. MicroRNA control of signal transduction. Nat Rev Mol Cell Biol. 2010;11:252-63.

18. Zhou S, Schuetz JD, Bunting KD, Colapietro AM, Sampath $\mathrm{J}$, Morris JJ, et al. The ABC transporter Bcrp1/ABCG2 is expressed in a wide variety of stem cells and is a molecular determinant of the side-population phenotype. Nat Med. 2001;7:1028-34.

19. Gerber JM, Smith BD, Ngwang B, Zhang H, Vala MS, Morsberger L, et al. A clinically relevant population of leukemic CD34(+)CD38(-) cells in acute myeloid leukemia. Blood. 2012;119:3571-7.

20. Luo Z, Wen G, Wang G, Pu X, Ye S, Xu Q, et al. MicroRNA-200C and -150 Play an Important Role in Endothelial Cell Differentiation and Vasculogenesis by Targeting Transcription Repressor ZEB1. Stem Cells. 2013;31:1749-62.

21. Bitarte N, Bandres E, Boni V, Zarate R, Rodriguez J, Gonzalez-Huarriz M, et al. MicroRNA-451 is involved in the self-renewal, tumorigenicity, and chemoresistance of colorectal cancer stem cells. Stem Cells. 2011;29:1661-71.

22. Schadt EE. Molecular networks as sensors and drivers of common human diseases. Nature. 2009;461:218-23.

23. Wang K, Li M, Hakonarson H. Analysing biological pathways in genome-wide association studies. Nat Rev Genet. 2010;11:843-54.

24. Ramakrishnan V, Kimlinger T, Haug J, Painuly U, Wellik L, Halling T, et al. Anti-myeloma activity of Akt inhibition is linked to the activation status of PI3K/Akt and MEK/ ERK pathway. PLoS One. 2012;7:e50005.

25. Li J, Zhu J, Cao B, Mao X. The mTOR Signaling Pathway is an Emerging Therapeutic Target in Multiple Myeloma. Curr Pharm Des. 2014;20:125-35.

26. Mao X, Cao B, Wood TE, Hurren R, Tong J, Wang X, et al. A small-molecule inhibitor of D-cyclin transactivation displays preclinical efficacy in myeloma and leukemia via phosphoinositide 3-kinase pathway. Blood. 2011;117:198697.

27. Kellner J, Liu B, Kang Y, Li Z. Fact or fiction--identifying the elusive multiple myeloma stem cell. J Hematol Oncol. 2013;6:91.

28. Yang Y, Shi J, Tolomelli G, Xu H, Xia J, Wang H, et al. RARalpha2 expression confers myeloma stem cell features. Blood. 2013;122:1437-47.

29. Bandres E, Bitarte N, Arias F, Agorreta J, Fortes P, Agirre $\mathrm{X}$, et al. microRNA-451 regulates macrophage 
migration inhibitory factor production and proliferation of gastrointestinal cancer cells. Clin Cancer Res. 2009; 15:2281-90.

30. Zhu H, Wu H, Liu X, Evans BR, Medina DJ, Liu CG, et al. Role of MicroRNA miR-27a and miR-451 in the regulation of MDR1/P-glycoprotein expression in human cancer cells. Biochem Pharmacol. 2008;76:582-8.

31. Owonikoko TK, Khuri FR. Targeting the PI3K/AKT/mTOR Pathway. Am Soc Clin Oncol Educ Book. 2013;2013:395401.

32. Bergsagel PL, Kuehl WM, Zhan F, Sawyer J, Barlogie B, Shaughnessy J Jr. Cyclin D dysregulation: an early and unifying pathogenic event in multiple myeloma. Blood. 2005;106:296-303. 